\title{
Preparation and Characterization of Jute Cellulose Crystals-Reinforced Poly(L-lactic acid) Biocomposite for Biomedical Applications
}

\author{
Mohammed Mizanur Rahman, ${ }^{1}$ Sanjida Afrin, ${ }^{1}$ Papia Haque, ${ }^{1}$ Md. Minhajul Islam, \\ Mohammed Shahidul Islam, ${ }^{1}$ and Md. Abdul Gafur ${ }^{2}$ \\ ${ }^{1}$ Department of Applied Chemistry and Chemical Engineering, University of Dhaka, Dhaka 1000, Bangladesh \\ ${ }^{2}$ PP and PDC, Bangladesh Council for Scientific and Industrial Research, Dhaka 1205, Bangladesh
}

Correspondence should be addressed to Mohammed Mizanur Rahman; mizanur.rahman@du.ac.bd

Received 25 August 2013; Revised 23 November 2013; Accepted 29 November 2013; Published 16 February 2014

Academic Editor: Donald L. Feke

Copyright (C) 2014 Mohammed Mizanur Rahman et al. This is an open access article distributed under the Creative Commons Attribution License, which permits unrestricted use, distribution, and reproduction in any medium, provided the original work is properly cited.

\begin{abstract}
Crystalline cellulose was extracted from jute by hydrolysis with $40 \% \mathrm{H}_{2} \mathrm{SO}_{4}$ to get mixture of micro/nanocrystals. Scanning electron microscope (SEM) showed the microcrystalline structure of cellulose and XRD indicated the $\mathrm{I}_{\beta}$ polymorph of cellulose. Biodegradable composites were prepared using crystalline cellulose (CC) of jute as the reinforcement (3-15\%) and poly(lactic acid) (PLA) as a matrix by extrusion and hot press method. CC was cellulose derived from mercerized and bleached jute fiber by acid hydrolysis to remove the amorphous regions. FT-IR studies showed hydrogen bonding between the CC and the PLA matrix. The $\mathrm{X}$-ray diffraction (XRD) and differential scanning calorimetry (DSC) studies showed that the percentage crystallinity of PLA in composites was found to be higher than that of neat PLA as a result of the nucleating ability of the crystalline cellulose. Furthermore, Vicker hardness and yield strength were found to increase with increasing cellulose content in the composite. The SEM images of the fracture surfaces of the composites were indicative of poor adhesion between the CC and the PLA matrix. The composite with $15 \%$ CC showed antibacterial effect though pure films but had no antimicrobial effect; on the other hand its cytotoxicity in biological medium was found to be medium which might be suitable for its potential biomedical applications.
\end{abstract}

\section{Introduction}

Considering the huge benefits of environmentally friendly materials, the use of natural/biofiber reinforced composites has rapidly expanded due to the availability of such renewable resources, for use as reinforcing composites with other synthetic and biodegradable polymer matrices (biocomposite) $[1,2]$. In addition, the low cost and high specific properties of these natural fibers provide significant performance with advantages and economic benefits when combined with biodegradable polymers [1]. The development of biomaterials for regenerative medicine can be still considered an emerging field, with tissue engineering, and especially bone implants, being a fast-growing branch of this research area [3]. In order to produce fully renewable and biodegradable composites, both the polymer matrix and the reinforcement have to be derived from renewable resources.

Crystalline cellulose (CC), where the amorphous regions are removed by acid hydrolysis, can be a very promising cellulosic reinforcement for polymers. Native cellulose is one of the strongest and stiffest natural fibers available; the theoretical modulus is estimated at $167.5 \mathrm{GPa}$ [4], and it has a high potential to act as reinforcing agent in biopolymers. CC has the advantage of high specific surface area compared to other conventional cellulose fibers [5]. CC especially cellulose nanocrystals has attracted significant attention during the last decade as potential nanoreinforcement in different polymers [6]. Biocompatible materials involving biopolymers, such as collagen and poly(lactic acid) (PLA), are the most widely studied materials for the regeneration of damaged 
tissues, acting as artificial supports for cell growth. PLA is mainly used in biomedical applications is the first commodity plastic produced from fully renewable resources [2, 7]. PLA can therefore vary from being an amorphous polymer to semicrystalline or highly crystalline material $[8,9]$. The processability of PLA is equivalent to that of petroleumbased synthetic materials and its mechanical properties are considered to be broadly similar to those of conventional petroleum-based polymers $[8,10]$. A low softening temperature results in a low temperature use of the material, which in turn will limit the number of applications of the material.

Preparation of composites has been considered a promising method to increase the softening temperature of biopolymers. Therefore, it is interesting to study if the incorporation of reinforcements can improve the toughness and thermal stability. Oksman et al. [11] produced flax fiber reinforced PLA composites by extrusion and compression molding. They found enhanced mechanical properties of the composite than pure PLA film. It was reported that tensile strength of the composites increased from 44.5 to $54.1 \mathrm{MPa}$ and Young's modulus increased from 3.1 to $6.31 \mathrm{GPa}$ as the fiber content increased from 0 to $30 \mathrm{wt} \%$ respectively. MCC up to $25 \%$ of wood flour PLA composite was compounded using a twin-screw extruder and injection-molding to improve the thermal stability and storage modulus of the composites [12]. "Green"/biobased composites were prepared from poly(lactic acid) (PLA) and recycled cellulose fibers (from newsprint) by extrusion followed by injection-molding processing. The physicomechanical and morphological properties of the composites were investigated which showed that recycle newsprint could be another source for CC preparation for composite with PLA [13].

Although there was significant work already done for the preparation of crystalline cellulose-PLA from different sources such as wood, cotton, and sisal, there was no report in the literature which addresses the application of jute cellulose crystals for biocomposite preparation with PLA. In all literature the composites were characterized by conventional techniques such as thermal, morphological, flexural, and hardness, but no biological properties are addressed. In the present study, micro- and nanocrystalline cellulose are prepared from jute by sulfuric acid hydrolysis of mercerized and bleached jute fiber. The cellulose crystals will be used to reinforce biocomposite with PLA by extrusion and heat press molding. The extensive mechanical, thermal, morphological, and bioactive characteristics of the composites are evaluated to determine its suitability for biomedical applications.

\section{Experimental}

2.1. Materials. Jute-white Corchorus capsularis was purchased from the local market of Tangail, Bangladesh. PLA (3251D, Nature Works, USA) was kindly donated by Dr. Ifty Ahmed, Polymer Composite Group, Faculty of Engineering, University of Nottingham, UK. The molecular weight and the polydispersity of the PLA were 2100 (Mn) and 2.1 (PDI) and optically transparent.
TABLE 1: Composition of PLA/cellulose composites.

\begin{tabular}{lcc}
\hline Film & Amount of CC, g & Amount of PLA, g \\
\hline Film with 0\% cellulose & 0.00 & 5.00 \\
Film with 3\% cellulose & 0.15 & 4.85 \\
Film with 6\% cellulose & 0.30 & 4.70 \\
Film with 12\% cellulose & 0.60 & 4.40 \\
Film with 15\% cellulose & 0.75 & 4.25 \\
\hline
\end{tabular}

\subsection{Methods}

2.2.1. Extraction of Cellulose Crystals from Jute. Jute fibers were subjected to a washing pretreatment to remove impurities and waxy substances covering the external surface of fiber cell walls. The fibers were milled into fine size $(\sim 0.1 \mathrm{~mm}$ size $)$ by using a mechanical milling machine. These fibers $(25 \mathrm{~g})$ were dispersed in distilled water $(500 \mathrm{~mL})$ for $10 \mathrm{~min}$ at room temperature and stirred for $2 \mathrm{~h}$ at $50^{\circ} \mathrm{C}$ using a glass rod and filtered in order to remove soluble extractives in water. The dried fiber was then mercerized with $2 \% \mathrm{NaOH}$ solution at $80^{\circ} \mathrm{C}$ for $6 \mathrm{~h}$ followed by thorough washing and drying. The dried fiber was bleached with $2 \% \mathrm{NaClO}_{2}$ at $80^{\circ} \mathrm{C}$ for $4 \mathrm{~h}$ and washed and dried in an oven. The bleached fibers were treated in a concentrated sulfuric acid solution ( $40 \mathrm{wt} \%$ sulfuric acid in water) at $45^{\circ} \mathrm{C}$ for $10 \mathrm{~h}$ using a mechanical stirrer and the fibers to acid solution ratio was maintained, $1: 15 \mathrm{gmL}^{-1}$. After treatment, the hydrolyzed cellulose samples were neutralized by $30 \% \mathrm{NaOH}$ solution, and then the crystals were washed for 4 times and separated from the solution by centrifugation $(8,000 \mathrm{rpm}, 10 \mathrm{~min})$ after each washing step. The resultant cellulose crystals were freeze dried for 48 hours.

\subsubsection{Preparation of CC Reinforced Poly(lactic acid) (PLA)}

Film. Preparation of cellulose reinforced poly(lactic acid) composite consists of two steps: extrusion and hot press. The composition of the CC reinforced PLA composites are shown in Table 1. The extrusion process of cellulose-PLA composites renders several challenges. The major difficulty is to feed the CC into the extruder and achieve uniformly dispersed CC in the polymer matrix. The CCs have a very high surface area and have a tendency to aggregate when dried. Therefore, to avoid the reaggregation during drying, the whisker or crystalline cellulose was suspended in N,Ndimethylformamide (DMF) and the suspension was directly fed into the polymer melt during the extrusion process. The composite materials were compounded using a Dynisco LME Laboratory Mixing Extruder. The process temperatures of the outside and inside header of the extruder are 75 and $80^{\circ} \mathrm{C}$ with a screw rotation of $25 \mathrm{rpm}$. PLA pellets and CC were dried first at a vacuum oven to remove moisture. The samples were placed in a cooled hopper where they fell onto the hot surface of a cylindrical rotor. The sample mixture is melted through heat conduction created by the mechanical work of the turning rotor. When sufficiently melted, the extruded samples moved to the outlet dye and exit through the orifice.

After extrusion, the cylindrical rod-like samples were cut into small size $(1.5 \mathrm{~cm}$ long) and arranged on an in-lab 
made dye, which has a ring of inside diameter $8 \mathrm{~cm}$ and outside diameter of $12 \mathrm{~cm}$ and has two discs on each side each of $1.5 \mathrm{~cm}$ in thickness. Then the samples in the dye were hot pressed in between two plates of a hot press (Weber Pressen Hydraulic Press) for 2-3 min after reaching process temperature of $165^{\circ} \mathrm{C}$.

\subsubsection{Characterization of the Crystals and the Composites.} The dried CC sample and the composites were analyzed by an ATR-FTIR spectrophotometer (Model-01831, SHIMADZU Corp., Japan). Crystal's structure was monitored by a D8 Advance X-ray diffractometer, employing $\mathrm{Cu}$ radiation of wavelength $\lambda=1.54$ and a graphite monochromator with a current of $30 \mathrm{~mA}$, and voltage of $30 \mathrm{mV}$ was used to evaluate the cellulose and composite specimen. The diffraction intensity was in the range of $5^{\circ}$ to $30^{\circ}$ of $2 \theta$ (Bragg angle) and the scanning speed was $0.02^{\circ} \mathrm{sec}^{-1}$. Surface morphology of both CCs and the biocomposites was observed by a scanning electron microscope (SEM) (JEOL JSM-6490LA, Japan).

Thermal properties were monitored by thermogravimetric analysis (TGA) and differential thermal analyses (DTA) of cellulose and the composites were performed by using a TG/DTA EXTAR 6000 STATION, Seiko Instrument Inc., Japan. Thermomechanical analysis (TMA) of the scaffold film was carried out by using a Shimadzu TMA-50 analyzer, Japan. The sample $(4 \mathrm{~mm} \times 4 \mathrm{~mm})$ was cut and placed in an aluminum crucible, and a lid was placed over the sample under a constant load of $100 \mathrm{mN}$ and then heated up to $170^{\circ} \mathrm{C}$ from $20^{\circ} \mathrm{C}$ with a heating rate of $5^{\circ} \mathrm{C} \mathrm{min}^{-1}$ in nitrogen atmosphere. The crystallization behaviors of the raw materials and the composites were carried out by using a DSC-60(SHIMADZU Corp., Japan). The sealed aluminium pan was put on the calorimeter along with an empty sealed pan. Change of heat per gram of sample was recorded at a constant temperature for 60 minutes with a computerized system under nitrogen atmosphere. The heating for TG/DTA was done at a rate of $5^{\circ} \mathrm{C} \mathrm{min}^{-1}$ under nitrogen atmosphere.

2.2.4. Mechanical Properties. The composites prepared from PLA and CC by extrusion and hot press method are highly brittle, and it is difficult to measure their tensile properties and in that cause surface hardness and yield strength were determined. Microhardness testing was done according to ASTM E-384 method, which gives an allowable range of loads for testing with a diamond indenter; the resulting indentation is measured and converted to a hardness value. The result for Vickers' microhardness was reported in $\mathrm{kg} / \mathrm{cm}^{2}$.

2.2.5. Microbial Sensitivity and In Vitro Cytotoxicity Study. Identification of sensitivity of bacteria (Bacillus subtilis and Escherichia coli) to cellulose reinforced PLA composites has been shown by Microbial Sensitivity test. Kirby-Bauer method has been followed to carry out this test. In vitro, cytotoxicity test was performed using brine shrimp lethality bioassay method [14]. Brine shrimps (Artemia salina) were hatched using brine shrimp eggs in a conical shaped vessel $(1 \mathrm{~L})$, filled with sterile artificial seawater and $\mathrm{pH}$ was adjusted at 8.5 using $0.1 \mathrm{~N} \mathrm{NaOH}$ under constant aeration for $48 \mathrm{~h}$.
After hatching, active nauplii free from egg shells were collected from brighter portion of the hatching chamber and used for the assay. Cellulose containing thin film was dissolved in artificial seawater, at $0.20 \mathrm{mg} \mathrm{mL}^{-1}$ concentration and was taken in Petri plates where the active nauplii were inoculated. After overnight incubation, the nauplii were counted. $0.5 \mathrm{mg} \mathrm{mL}^{-1}$ of vincristine sulfate (an anticancer drug) was considered as positive control.

\section{Results and Discussions}

3.1. Extraction of Micro- and Nanocrystalline Cellulose from Jute. Cellulose crystals can be prepared from delignified cellulose by acid hydrolysis [15]. This is because acid hydrolysis is effective in dissolving the amorphous cellulose. Microand nanocrystalline cellulose extraction procedure from jute consists of washing, lignin removal, bleaching, and acid hydrolysis. When cellulosic fiber is treated with $\mathrm{NaOH}$, it changes the fine structure of the native cellulose I to cellulose II by a process known as mercerization [16]. The reaction of sodium hydroxide with cellulose is thought to be as follows:

Cell-OH $+\mathrm{NaOH}=$ Cell- $\mathrm{ONa}+\mathrm{H}_{2} \mathrm{O}+$ surface impurities.

Alkali treatment can remove natural and artificial impurities and produce rough surface topography as shown in Figure 1. Therefore, the mechanical interlocking at the interface would be improved. The mercerized fiber was then subjected to acid treatment with $40 \%$ sulfuric acid followed by washing and separation through a centrifuge. It is noteworthy to mention that we have tried several times to hydrolyze with $64 \%$ acid as mentioned in the literature $[17,18]$; however, the substance was burnt due to higher acid concentration, and for this reason, we have used $40 \%$ though it is not feasible to extract nanocrystals only; thus, we obtained a mixture of nano- and microcrystalline cellulose, were dominated mainly by microcrystalline cellulose particles.

3.2. Morphological Study. The images of the CC and the composites as obtained by SEM are shown in Figure 1. It can be seen from the figure that the CC appeared in micro and nanorod-like structure, and the diameter of microcrystals is in the range of about 5-6 $\mu \mathrm{m}$, having an aspect ratio $(l / d)$ around 6-7 (Figure 3(c)). It is also possible to see some nanofibrils on the CC particle surfaces although it is not clearly detectable due to the limitation of SEM, which might be evidence that the CC particles are agglomerated of hundreds of individual cellulose nanofibrils. The extruded composite was dark in color (as shown in Figure 1(e)), may be due to the reason of not using any modifier and some sort of degradation of cellulose during processing. The composite films were black, though the ground composite (in powder form) was white. Figure 1(f) is an overview of PLA/CC composites showing a uniform dispersion of CC in the PLA matrix. Here cellulose crystals are clearly observed, and they show some agglomeration in some region resulted from improper mixing. 


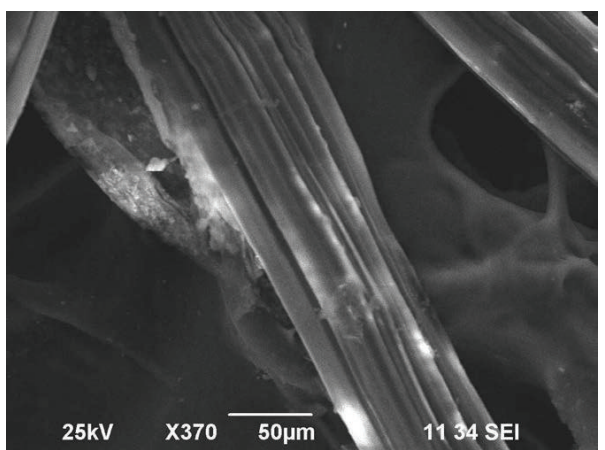

(a)

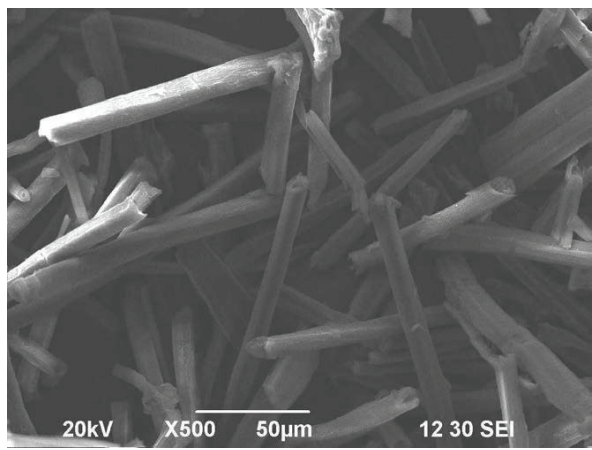

(c)

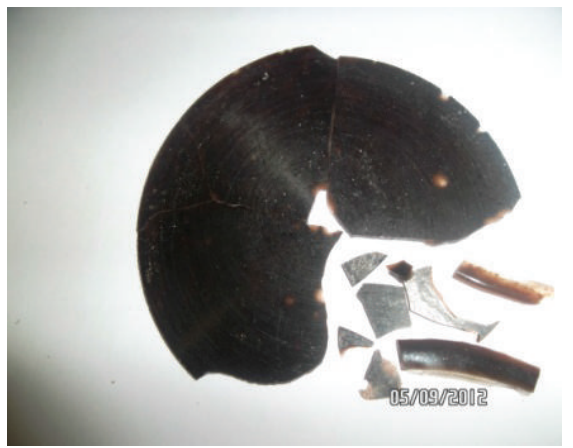

(e)

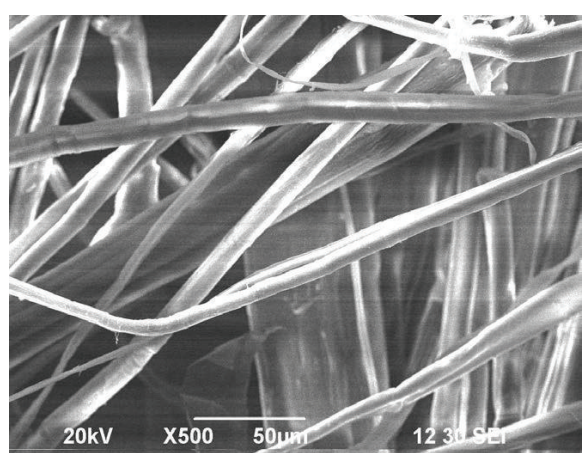

(b)

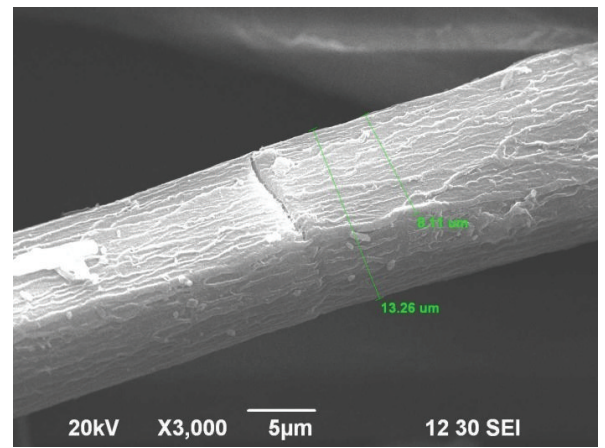

(d)

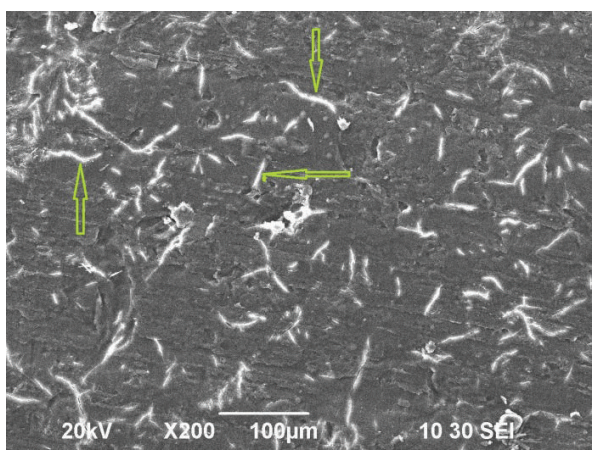

(f)

FIGURE 1: SEM images of CCs and biocomposite. (a) Mercerized jute, (b) bleached jute, (c) and (d) acid hydrolyzed jute, (e) picture of composite, and (f) image of PLA/CC biocomposite with 15\% CC.

3.3. FTIR Study. FTIR spectra of CCs and CC-PLA composites are given in Figure 2. The peaks of $\mathrm{C}-\mathrm{O}$ stretching vibration occur in the range of $1435-650 \mathrm{~cm}^{-1}$. Among them, $1047 \mathrm{~cm}^{-1}$ and $1253 \mathrm{~cm}^{-1}$ are attributed to the saccharide structure. The bending of $\mathrm{C}-\mathrm{O}-\mathrm{H}$ appeared as a broad and weak peak at $1435-1253 \mathrm{~cm}^{-1}$. The $\mathrm{C}-\mathrm{H}$ stretching peak and hydrogen bonded $\mathrm{O}-\mathrm{H}$ stretching vibration (broad band) occur at 2897 and $3369 \mathrm{~cm}^{-1}$, respectively.

Pure PLA showed a strong absorption band at $1751 \mathrm{~cm}^{-1}$ corresponding to the stretching vibration carbonyl group ($\mathrm{C}=\mathrm{O}$ ) from the repeated ester units. The $-\mathrm{C}-\mathrm{O}-$ stretching vibration from the ester units was observed at 1180, 1129, and $1082 \mathrm{~cm}^{-1}$. The bands at 2996 and $2877 \mathrm{~cm}^{-1}$ were assigned to the $-\mathrm{C}-\mathrm{H}$ asymmetric and symmetric vibration of $\mathrm{CH}_{3}$ groups in the side chains. The band at $2948 \mathrm{~cm}^{-1}$ was attributed to the - $\mathrm{CH}$ - groups in the main chain of PLA [19]. The band of composites shifted to the higher wave number from 1751 to $1761 \mathrm{~cm}^{-1}$. Auras et al. [19] stated that this was caused by the formation of intermolecular $\mathrm{H}$-bonding. The peak at $1751 \mathrm{~cm}^{-1}$ was gradually disappeared in the composites with higher cellulose content.

3.4. XRD Analysis. The XRD analysis of the raw materials and the biocomposites was done to obtain further insight into the materials' crystallinity. The XRD patterns of PLA, $\mathrm{CC}$ and composite are shown in Figure 3. PLA exhibits a small and broad peak at $2 \theta=14.4$ with one less prominent peak and can be considered as semicrystalline in nature. CC shows peaks at $2 \theta=15.4$ and 22.5 and these peaks are more prominent and sharp for CC showing the crystalline 


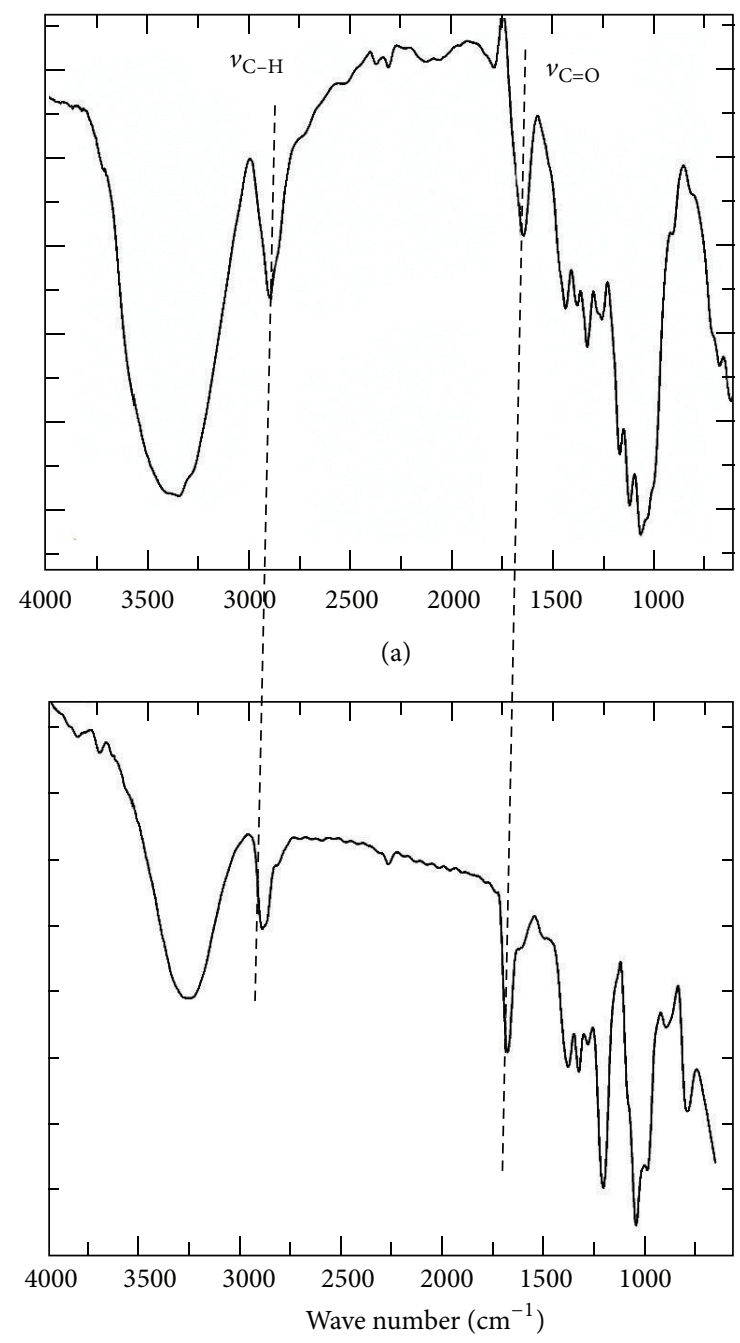

(b)

FIGURE 2: FTIR spectra of (a) jute cellulose crystals and (b) CC-PLA biocomposite.

nature of this reinforcement. The interplaner spacing $(d)$ values associated with $2 \theta=15.4$ and 22.5 are 6.14 and $3.95 \AA$ which corresponds to cellulose I polymorph structure. The peaks around $2 \theta=16^{\circ}$ and $19^{\circ}$ correspond to the crystalline structure of PLA, and the peak positions are in accordance with those reported by Mathew et al. [12]. The higher crystallinity of PLA-cellulose composites compared to neat PLA showed that cellulose has incorporated more crystallization into PLA composite because cellulose acts as a nucleating agent accelerating the crystallization of PLA.

3.5. Thermal Properties. The results from the TGA, DTG, and DTA are presented in Figure 4, which shows the residual weight versus temperature for PLA, CC, and composite materials. The results showed that all materials were thermally stable in the region below $280^{\circ} \mathrm{C}$. The recommended processing temperature of PLA is $200^{\circ} \mathrm{C}$ and both CC and composites could maintain more than $95 \%$ of their original

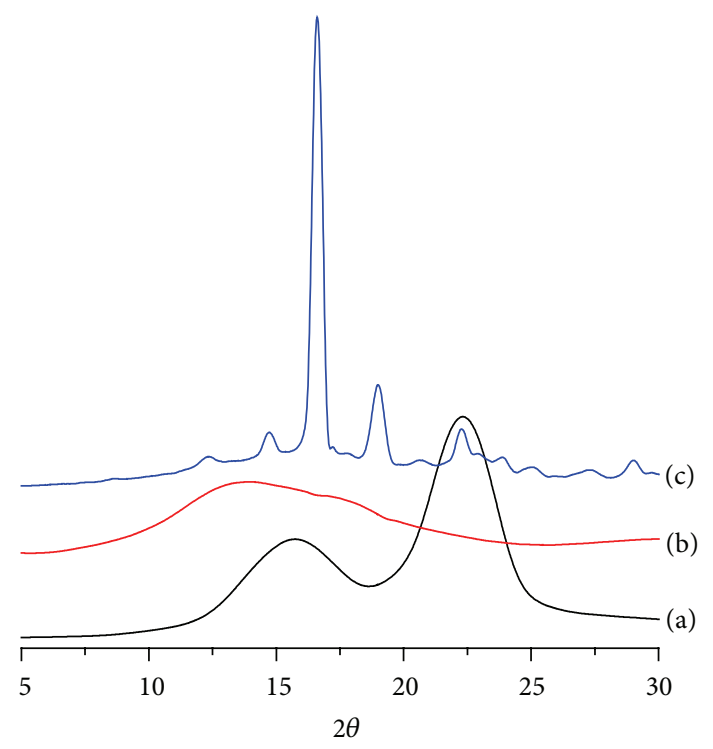

FIGURE 3: XRD patterns of (a) cellulose, (b) PLA, and (c) PLA crystalline cellulose biocomposite.

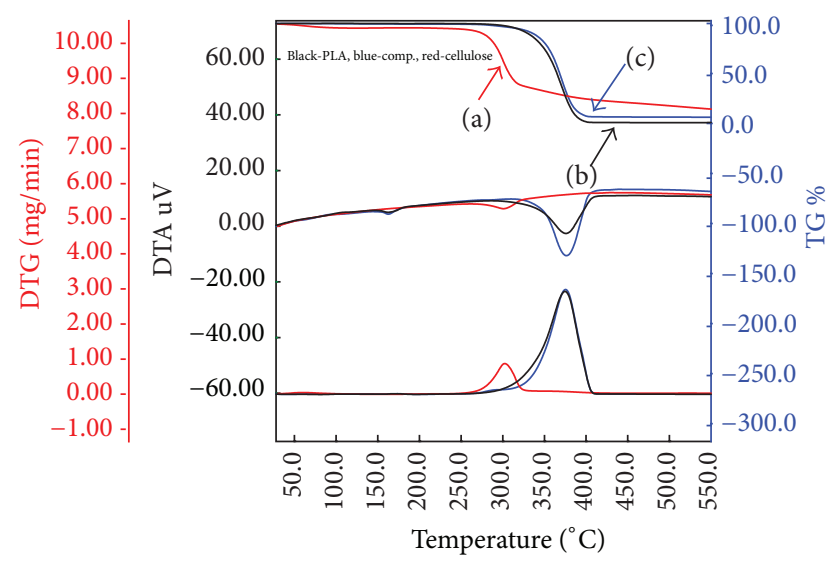

Figure 4: Comparison of TG/DTA and DTG value of (a) cellulose crystals (red), (b) PLA (black), and (c) biocomposite (blue).

weight at this temperature. TG of CC shows the 3.9\% initial loss due to moisture. Then the mass is continuously losing having initial slower rate and ending is in the faster rate. The temperatures at the maximum slope (50\% degradation) were $283.5^{\circ} \mathrm{C}$ and $301.0^{\circ} \mathrm{C}$. The DTA curve showed two endothermic peaks at $301.0^{\circ} \mathrm{C}$ and $413.2^{\circ} \mathrm{C}$ due to thermal degradation. TG of PLA shows no initial loss due to moisture as PLA is highly hydrophobic in nature and total degradation was $99.5 \%$; however, it was only $82 \%$ for CC and $91.8 \%$ for $15 \%$ CC containing composites.

Thermomechanical analysis (TMA) microgram of pure PLA and its composite with $15 \%$ cellulose are shown in Figure S1 in the supporting information. Figure S1(a) for PLA showed total contraction and it showed two peaks at $60.7^{\circ} \mathrm{C}$ and at $157.8^{\circ} \mathrm{C}$ which indicated the softening point and melting point of PLA, respectively. Figure S1(b) showed two peaks at $52.2^{\circ} \mathrm{C}$ and $154.1^{\circ} \mathrm{C}$ which indicate the softening point 
and melting point, respectively, indicating that CC has less effect on softening and melting of the composite.

3.6. DSC Analysis of Cellulose and PLA/Cellulose Composites. DSC analysis was performed to investigate the crystallinity of the PLA and composite samples. Figure 5 shows the thermograms of DSC for CC, PLA, and composites at different CCs (6\% and 15\%) content obtained by heating scans. The thermogram of unannealed neat PLA showed the glass transition temperature $\left(T_{g}\right)$, cold crystallization temperature $\left(T_{c}\right)$, and melt temperature $\left(T_{m}\right)$, which are typical of semicrystalline polymer. It can be seen that $T_{g}$, $T_{c}$, and $T_{m}$ decrease with the addition of fiber to the PLA. The depression of glass transition, cold crystallization, and melt temperatures is typical for PLA, where enhanced chain mobility promotes crystallinity [20]. $T_{g}$ can increase or decrease with the degree of crystallinity depending on the relative density of the amorphous and crystalline states. Most often the more orderly crystalline state has the higher density at $T_{g}$ and the noncrystalline molecular chains are constrained by being anchored to the immobile crystallites and $T_{g}$ increases. On rare occasions the crystalline state has a lower density than the amorphous material. In this case, less constraint on the noncrystalline chain segments increases the entropy causing $T_{g}$ to decrease. It can be seen from the figure that the addition of CC to PLA results in an increase in percentage crystallinity of the PLA matrix. This can be explained by the nucleating ability of CCs allowing the crystallization of PLA. As a result of the modification of fiber surfaces by alkali treatment, bonding between the fiber and PLA matrix improves due to increased interaction by increased potential hydrogen bonding and mechanical interlocking between them. The increased interaction of the fiber with the matrix PLA could further help the fiber surface to act as nucleation sites for the crystallization of PLA.

3.7. Mechanical Properties. As the PLA film and its composites were very fragile in nature Vickers hardness $(\mathrm{VH})$ test and yield strength (YS) measurement were carried out. From the experiment, it was found that both the hardness and yield strength of PLA composites increase in the incorporation of reinforcing agent (cellulose) in the PLA matrix. However, it was observed that no significant change occurred for increasing cellulose concentration from 3 to $15 \%$. It may be defined in the way that the test of indentation is a surface phenomenon; it is not affected much by the reinforcing agent that agglomerates in the lower portion. Figure 6 showed the variation of $\mathrm{VH}$ and $\mathrm{YS}$ at different cellulose contents.

3.8. Biological Study. After incubation it was found that only the same 10 (as shown in Figure S2 in the supporting information) PLA film with $15 \%$ cellulose showed antimicrobial effect as clear zone (13 $\mathrm{mm}$ diameter) of inhibition was found underneath and in the vicinity of these films placed onto the Escherichia coli bacterial culture. For Bacillus subtilis bacteria sample number 10 showed a clear zone ( $8 \mathrm{~mm}$ diameter) like the previous one. Among all the samples PLA composite film with $15 \%$ cellulose showed the best antibacterial effect against

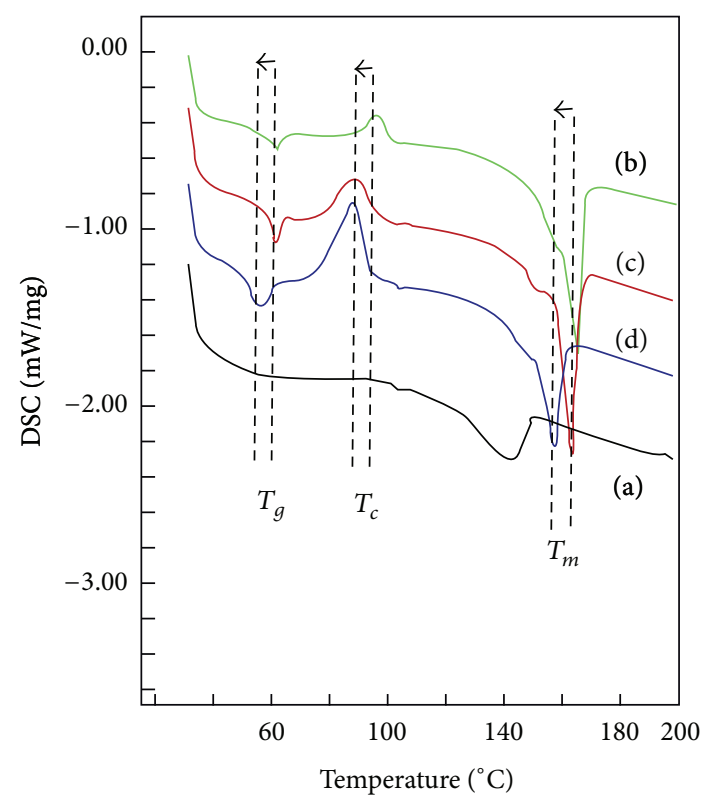

FIGURE 5: DSC thermogram of (a) jute CC, (b) PLA, (c) composite with $6 \% \mathrm{CC}$, and (d) composite with $15 \% \mathrm{CC}$.

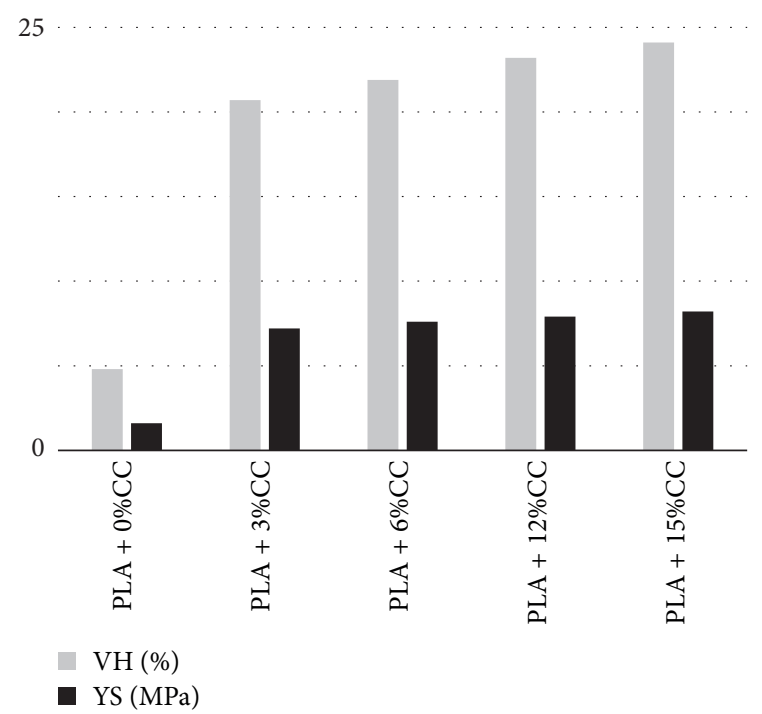

FIGURE 6: Variation of VH and YS at different cellulose contents.

both bacteria. In the present work, the possibility of deaths of nauplii due to toxicity is very low as the number of death was nil for lower concentrations (as shown in Table 2). Moreover, PLA and cellulose microfibrils were used as parent materials of the bone implant which were all biocompatible.

\section{Conclusion}

The increasing demand of the bioabsorbable composites for the biomedical purposes leads to the responsibility and obligation of researchers to develop products with better properties compared with those of existing materials. In this research work, we have extracted nano- and microcrystalline 
TABLE 2: Mortality of brine shrimp (Artemia salina) nauplii at different concentrations of cellulose/PLA thin film.

\begin{tabular}{lcccc}
\hline Sample no. & Sample name & Dose $(\mathrm{mg} / \mathrm{L})$ & Number of nauplii present after incubation & Mortality $(\%)$ \\
\hline 1 & Positive control (vincristine sulfate) & 0.5 & 0 & 10 \\
2 & Negative control (artificial sea water) & - & 10 & 0 \\
3 & Film with 0\% cellulose & 0.2 & 8 & 0 \\
4 & Film with 3\% cellulose & 0.2 & 9 & 20 \\
5 & Film with 6\% cellulose & 0.2 & 8 & 10 \\
6 & Film with 15\% cellulose & 0.2 & & 20 \\
\hline
\end{tabular}

cellulose from jute and various reaction parameters were optimized in a view to obtain high extraction yield. The crystalline cellulose was used to fabricate composite with PLA. It was observed that hydrogen bonding exists between CC and PLA when the composite was fabricated by extrusion or hot press. The thermal stability and the crystallinity of the composites have increased when composite was prepared from CC and PLA. Vickers hardness test cellulose/PLA composite prepared from 15\% CC showed maximum hardness and also that showed better antimicrobial properties. All these properties suggest that the composite can be used in biomedical purposes such as regenerative bone tissue.

\section{Conflict of Interests}

The authors declare that there is no conflict of interests regarding the publication of this paper.

\section{References}

[1] A. Mohanty, M. Misra, and G. Hinrichsen, "Biofibres, biodegradable polymers and biocomposites: an overview," Macromolecular Materials and Engineering, vol. 276, pp. 1-24, 2000.

[2] A. K. Mohanty, M. Misra, and L. T. Drzal, "Sustainable BioComposites from renewable resources: opportunities and challenges in the green materials world," Journal of Polymers and the Environment, vol. 10, no. 1-2, pp. 19-26, 2002.

[3] E. L. Chaikof, H. Matthew, J. Kohn, A. G. Mikos, G. D. Prestwich, and C. M. Yip, "Biomaterials and scaffolds in reparative medicine," Annals of the New York Academy of Sciences, vol. 961, pp. 96-105, 2002.

[4] W. Hamad, Cellulosic Materials: Fibers, Networks, and Composites, Springer, 2002.

[5] I. Siró and D. Plackett, "Microfibrillated cellulose and new nanocomposite materials: a review," Cellulose, vol. 17, no. 3, pp. 459-494, 2010.

[6] M. A. S. Azizi Samir, F. Alloin, and A. Dufresne, "Review of recent research into cellulosic whiskers, their properties and their application in nanocomposite field," Biomacromolecules, vol. 6, no. 2, pp. 612-626, 2005.

[7] S. S. Ray, K. Yamada, M. Okamoto, and K. Ueda, "Polylactidelayered silicate nanocomposite: a novel biodegradable material," Nano Letters, vol. 2, no. 10, pp. 1093-1096, 2002.

[8] D. Garlotta, "A literature review of poly(lactic acid)," Journal of Polymers and the Environment, vol. 9, no. 2, pp. 63-84, 2001.

[9] A. Södergård and M. Stolt, "Properties of lactic acid based polymers and their correlation with composition," Progress in Polymer Science, vol. 27, no. 6, pp. 1123-1163, 2002.
[10] C. Bastioli, "Global status of the production of biobased packaging materials," Starch-Stärke, vol. 53, pp. 351-355, 2001.

[11] K. Oksman, M. Skrifvars, and J.-F. Selin, "Natural fibres as reinforcement in polylactic acid (PLA) composites," Composites Science and Technology, vol. 63, no. 9, pp. 1317-1324, 2003.

[12] A. P. Mathew, K. Oksman, and M. Sain, "The effect of morphology and chemical characteristics of cellulose reinforcements on the crystallinity of polylactic acid," Journal of Applied Polymer Science, vol. 101, no. 1, pp. 300-310, 2006.

[13] M. S. Huda, A. K. Mohanty, L. T. Drzal, E. Schut, and M. Misra, “'Green' composites from recycled cellulose and poly(lactic acid): physico-mechanical and morphological properties evaluation," Journal of Materials Science, vol. 40, no. 16, pp. 42214229, 2005.

[14] J. L. Mclaughlin, L. L. Rogers, and J. E. Anderson, "The use of biological assays to evaluate botanicals," Drug Information Journal, vol. 32, no. 2, pp. 513-524, 1998.

[15] X. M. Dong, J.-F. Revol, and D. G. Gray, "Effect of microcrystallite preparation conditions on the formation of colloid crystals of cellulose," Cellulose, vol. 5, no. 1, pp. 19-32, 1998.

[16] J. Gassan and A. K. Bledzki, "Alkali treatment of jute fibers: relationship between structure and mechanical properties," Journal of Applied Polymer Science, vol. 71, no. 4, pp. 623-629, 1999.

[17] D. Bondeson, A. Mathew, and K. Oksman, "Optimization of the isolation of nanocrystals from microcrystalline cellulose by acid hydrolysis," Cellulose, vol. 13, no. 2, pp. 171-180, 2006.

[18] S. Elazzouzi-Hafraoui, Y. Nishiyama, J.-L. Putaux, L. Heux, F. Dubreuil, and C. Rochas, "The shape and size distribution of crystalline nanoparticles prepared by acid hydrolysis of native cellulose," Biomacromolecules, vol. 9, no. 1, pp. 57-65, 2008.

[19] R. Auras, B. Harte, and S. Selke, "An overview of polylactides as packaging materials," Macromolecular Bioscience, vol. 4, no. 9, pp. 835-864, 2004.

[20] A. J. Nijenhuis, E. Colstee, D. W. Grijpma, and A. J. Pennings, "High molecular weight poly(L-lactide) and poly(ethylene oxide) blends: thermal characterization and physical properties," Polymer, vol. 37, no. 26, pp. 5849-5857, 1996. 

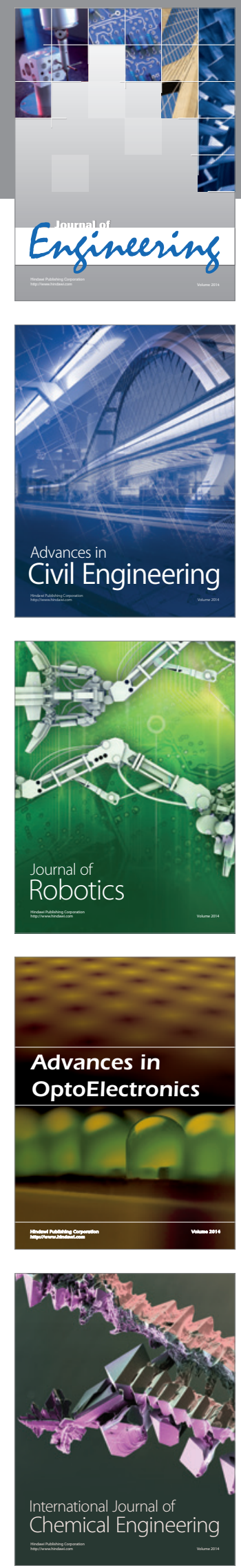

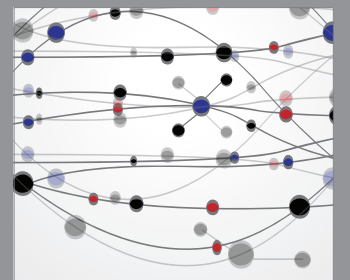

The Scientific World Journal
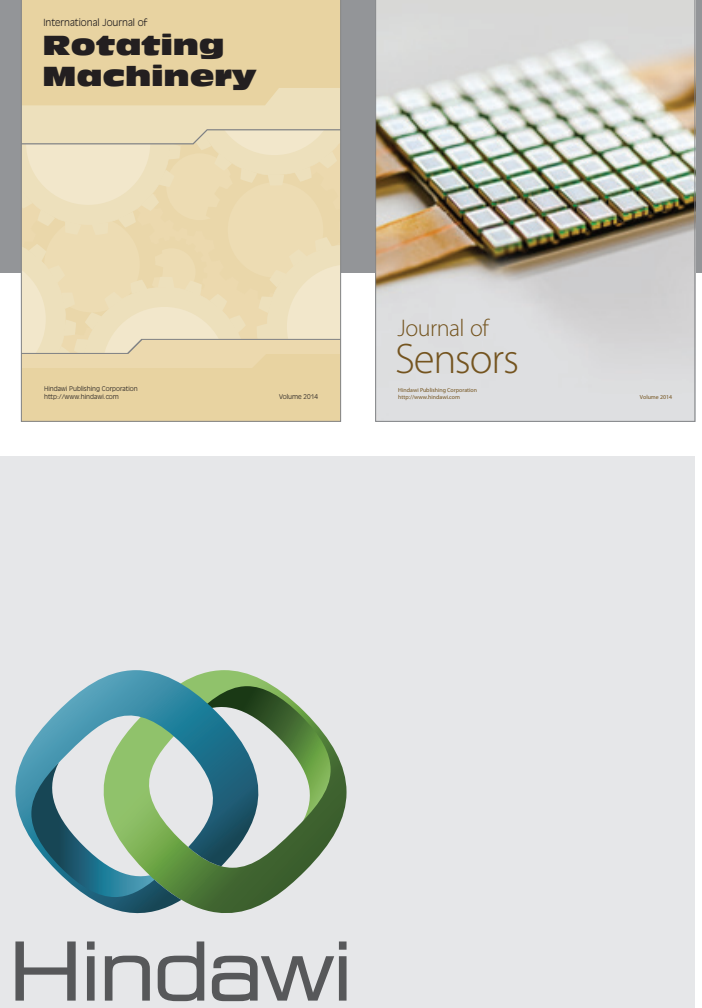

Submit your manuscripts at http://www.hindawi.com
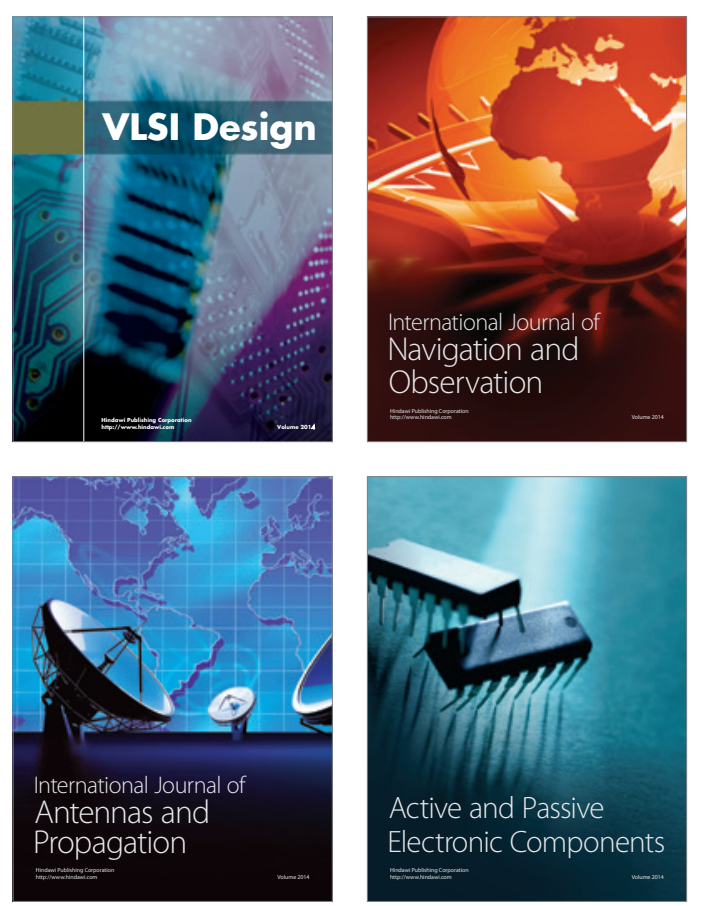
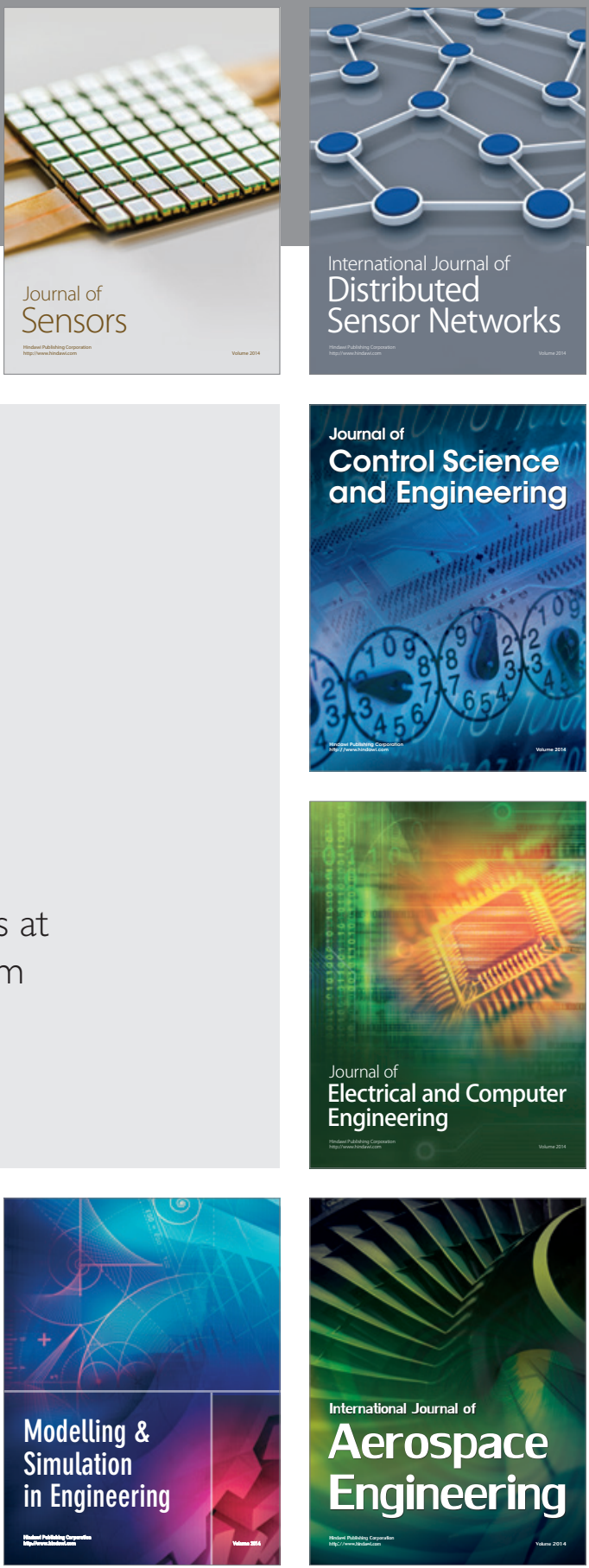

Journal of

Control Science

and Engineering
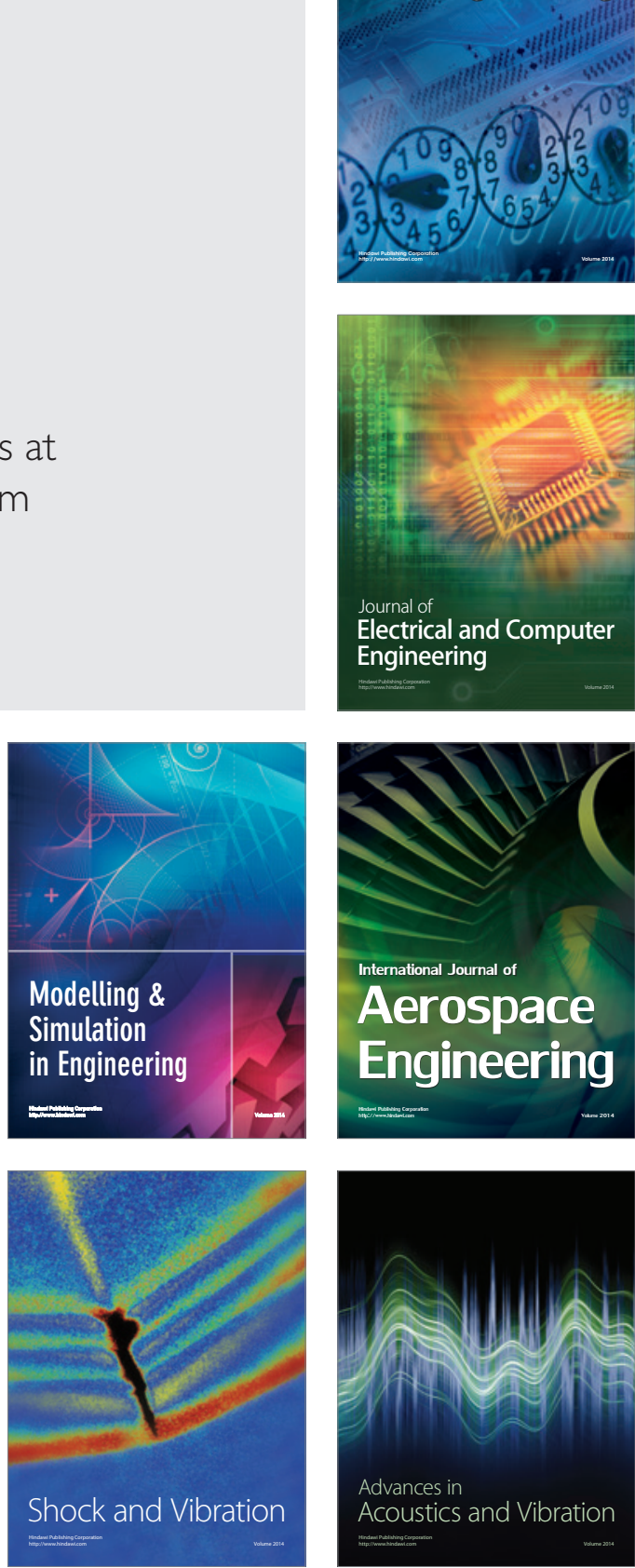